\title{
Prevalence of Intestinal Parasitic Infestation Among Hearing and Speech Impaired Children of Banke, Nepal
}

\author{
Rai $\mathrm{M}^{1}$, Neupane $\mathrm{GP}^{2}$, Dhami $\mathrm{DB}^{3}$, Paudel $\mathrm{TP}^{4}$
}

\begin{abstract}
Introduction: The parasites can cause different gastrointestinal disorders which have great impact on life quality. Hearing and speech impaired children are unable to maintain proper sanitation, making them more prone to intestinal parasitic infection. Aim and Objective: To know the prevalence of various parasitic infestations among hearing and speech impaired Children. Materials and Methods: Stool specimen were collected from 104 hearing and speech impaired children who were living in private rehabilitation school of chisapani village of Banke district Nepal for a period of 5 month from December 2017 to April 2018 and direct wet mount was prepared using normal saline (0.9\%) and Lugol's iodine $(0.5 \%)$. The wet mount was observed under microscope for parasites. Results: Among 104 individuals intestinal parasites were seen in $25.96 \%$ of students. Giardia lamblia (37.04\%) was the most common parasite followed by Ascaris lumbricoides (18.52\%) and Entamoeba histolytica (14.82\%). Conclusion: The study shows that although the speech and hearing impaired children are more prone to parasitic infection, the prevalence is same as normal people. Giardia lamblia, Ascaris lumbricoides and Entamoeba histolytica were the common parasites. Prompt diagnosis and treatment of infected children should be undertaken.
\end{abstract}

Key words: Infestation, intestinal parasites, prevalence

\section{INTRODUCTION}

Parasitic diseases have great impact on life quality of people all over the world particularly in developing countries. Actually, the prevalence of parasitic infections in a particular region depends not only on bioenvironmental situation, but also on social, economical, cultural conditions and physical status of person. In developing countries people have lack of access to health services, malnutrition, and poor sanitation increases vulnerability to infection with parasites ${ }^{1}$.

In south-east Asia Disability is a one of the major health problems with second and third highest prevalence rate of moderate disability and severe disability respectively. ${ }^{2}$ In Nepal $1.6 \%$ of total population are disabled with mobility disability being most common followed by speech and hearing, visual and finally intellectual disability ${ }^{3}$.

Due to the various disability, differently-abled people are unable to maintain proper sanitation, making them more prone to intestinal parasitic infection. About $60 \%$ of Nepalese are infected with one or more parasite with soil-transmitted helminthes being most common ${ }^{4}$.

1. Dr. Maya Rai

2. Dr. Ganesh Prasad Neupane

3. Dr. Dabal Bahadur Dhami

4. Mr. Thakur Prasad Paudel

Address for correspondence:

Dr. Maya Rai

Department of Microbiology

Nepalgunj Medical College and Teaching Hospital

Chisapani, Banke, Nepal

E-mail:ganeshpn2003@yahoo.com
It have been seen that there is wide variation in prevalence of parasitic infestation in physically disabled people all over the world. $^{2}$

The parasites can cause different gastrointestinal disorders such as diarrhoea, dysentery, vomiting, lack of appetite, abdominal distension, malnutrition and anaemia etc ${ }^{5,6}$.

The common intestinal parasites that are found in human are Giardia lamblia, Entamoeba histolytica, Ascaris lumbricoides, Trichuris trichiura, Ancylostoma duodenale etc ${ }^{7}$.

This study is aimed to know the prevalence of various parasitic infestations in hearing and speech impaired Children of Banke District.

\section{MATERIAL AND METHOD}

This descriptive - cross sectional study was carried out on 104 hearing and speech impaired children who were living in private rehabilitation school of Chisapani village of Banke district Nepal for a period of 5 month from December 2017 to April 2018. Informed consent was taken from the school teachers and also from students who were participating in the study with the help of teachers. A questionnaire on age, sex, family size, ethnic group etc was filled with help of available data at school. The students were provided with wide mouthed clean, dry, properly labelled plastic container for collection of samples. The collected sample were transferred to the Microbiology laboratory of Nepalgunj Medical college. A direct wet-mount was done using saline $(0.9 \%)$ and Lugol's lodine $(0.5 \%)$ mount and observed under the microscope for stool parasites. Formalin- ether concentration method was done for the sample which were negative in direct wet mount. Collected 
data were entered in Microsoft Office Excel 2007 and analyzed using SPSS Inc. Statistical Software Version 16.0

\section{RESULTS}

Out of 104 speech and hearing impaired children who were included in the study 29 (27.88\%) were female and 75 (72.12\%) were male and $25.96 \%$ of the speech and hearing impaired persons were positive for parasite. (Table I). Among positive cases 19 (70.37\%) were positive in direct smear and 8 (29.63\%) (Giardia -3, Entamoeba histolytica-1, Ascaris lumbricoides-2, Hookworm -1, Trichuris trichuria-1) were positive in formalinconcentration method (Indirect).

\begin{tabular}{|l|c|c|c|}
\hline Sex & $\begin{array}{c}\text { Total } \\
\text { Number }\end{array}$ & $\begin{array}{c}\text { Positive } \\
\text { Number }\end{array}$ & Percentage \\
\hline Male & 75 & 19 & $25.33 \%$ \\
\hline Female & 29 & 8 & $27.50 \%$ \\
\hline Total & 104 & 27 & $25.96 \%$ \\
\hline
\end{tabular}

Table I: Prevalence of intestinal parasites among school children according to sex.

\begin{tabular}{|l|c|c|}
\hline Type of Parasites & Total & Percentage \\
\hline Protozoa \\
\hline Cyst of Giardia lamblia & 10 & 37.04 \\
\hline Cyst of Entamoeba histolytica & 4 & 14.82 \\
\hline \multicolumn{2}{|l|}{ Helminths } \\
\hline Egg of Ascaris lumbricoides & 5 & 18.52 \\
\hline Egg of Hookworm & 3 & 11.11 \\
\hline Egg of Hymenolepis nana & 3 & 11.11 \\
\hline Egg of Trichuristrichiuria & 2 & 7.40 \\
\hline Total & $\mathbf{2 7}$ & $\mathbf{1 0 0}$ \\
\hline
\end{tabular}

Table II: Types of intestinal parasites detected from hearing and speech impaired school children

\section{DISCUSSION}

Parasitic infestations of the gastrointestinal tract are one of the most common infections worldwide. It has been estimated that some 3.5 billion people are affected, and 450 million are sick as a result of these infections ${ }^{8}$.

It was seen that prevalence of intestinal parasitic infestation among hearing and speech impaired children was $25.96 \%$ which is within the range shown by various studies done in general population at different geographic locations of Nepal by Chhetri et. al ${ }^{9}$ and Rai et $\mathrm{al}^{10}$. This shows there is equal chance of people getting infected in Nepal irrespective of their presence or absence of disability. A study done by Poudyalet. al ${ }^{2}$ on prevalence of intestinal parasitosis in differently-abled

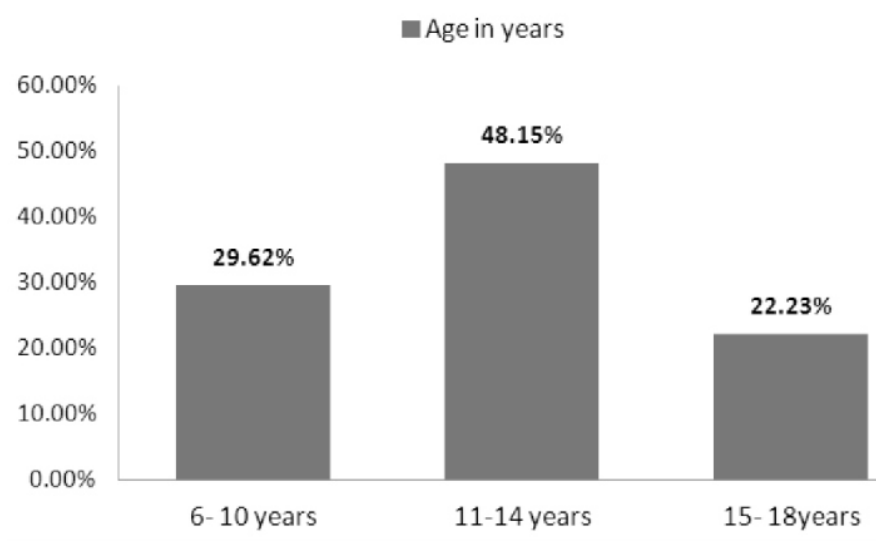

Figure 1: Prevalence of intestinal parasites among school children of different age-groups

The positive rates were $29.62 \%, 48.15 \%$ and $22.23 \%$ among children aged 6-10, 11-14and 15-18 years respectively (Figure 1). Six types of parasites were detected from hearing and speech impaired children among them two species were of protozoa and four species of helminthes.The most common intestinal parasite was found to be G. lambliain 10 (37.04 \%) of the cases, followed byAscarislumbricoides5 (18.52\%) (Table II).

persons was $32.1 \%$. The variation on prevalence of parasitic infestation could be be because of variation in social, economical, cultural conditions and physical status of person ${ }^{1}$. This study showed there was no difference in intestinal parasitosis prevalence among different sexes in hearing and speech impaired children which is in agreement to studies done by Poudyal et. al ${ }^{2}$ on differently-abled people.

In this study the higher prevalence $(48.15 \%)$ among children in the group aged 11-14 years appears to be associated with their activities. Children in this age group usually move around over a wider territory, increasing the possibility of acquiring infections from contaminated environment ${ }^{11}$.

In this study most common intestinal parasites detected from hearing and speech impaired school children was Giardia lamblia (37.04\%) which was similar to finding of Poudyal et al ${ }^{2}$ on differently-abled peoplehowever most common intestinal parasitic infection in Nepal is helminthes ${ }^{12}$. The high rate of G. lamblia may be due to continuous exposure to contaminated water ${ }^{2}$.

Ascarislumbricoides was second most common parasites found in this study followed by Entamoebahistolytica and Hookworm etc which was similar to finding of Poudyal et.al ${ }^{2}$. This appears to be due to the difficulty of complete removal of this parasite with a single dose of antihelminthic drug, particularly in those with heavy infection ${ }^{11}$. 


\section{CONCLUSIONS}

Parasitic infestation is a major public health problem in Nepal it becomes even more difficult to manage when associated with some disability like in hearing and speech impaired people. The study shows that although the hearing and speech impaired people are prone to parasitic infection, the prevalence is same as normal people. It may be because of transmission of infection by consumption of contaminated food and water. Giardia lamblia was most commonly detected intestinal parasites followed by Ascaris lumbricoides. The increasing trend of some parasites in the hearing and speech impaired children indicates the failure of maintaining good sanitation, personal hygiene, provision of safe drinking water, health education etc.Prompt diagnosis and treatment of infected children should be undertaken which will improve the overall health status of differently-abled children and help them live a comfortable life.

\section{Limitations:}

The limitations of the study are small sample size and study was conducted in single center only.

\section{REFRENCES}

1. Tappeh KH, Mohammadzadeh H, Nejad R, Barazesh A, Khashaveh SH, Taherkhani H. Prevalence of Intestinal Parasitic Infections among Mentally Disabled Children and Adults of Urmia, Iran. Iranian J Parasitol. 2010; 5(2):60-64.

2. Poudyal N, Shrestha LB, Gautam S, Yadav DK, Baral R, Gurung R. Prevalence of intestinal parasitic infection/infestation in differently abled people of Dharan, Nepal.International Journal of Biomedical Research. 2017;8(9): 538-40

3. World Health Organization. Disability in the South-East Asia Region, 2013. Regional office of South-East Asia: WHO Press; 2013.

4. Rai SK, Hirai K, Abe A, Ohno Y. Infectious Diseases and Malnutrition Status in Nepal: an Overview. Mal J Nutr2002; 8(2): 191-200.

5. Bethony J, Brooker S, Albanico M, Geiger M, Loukas A, Diemert D et al. Soil-transmitted helminth infections; Ascaris, Trichuriasis and hookworm. Lancet. 2006; 367(9521):1521-1532.

6. Awasthi HS, Bundy DAP and Lorenzo Savioli L. Helminthic infections. BMJ 2003; 327:431-433.

7. Gyawali N, Amatya R, Nepal HP. Intestinal parasitosis in school going children of Dharan municipality, Nepal. Trop Gastroenterol. 2009; 30:145-147.

8. Baral R, Jha P, Amatya R, Khana B. Prevalence of intestinal parasitic infections among patients attending in a tertiary care hospital of eastern region of Nepal - A retrospective, laboratory based study. Asian Journal of Medical Sciences. 2017; 8(3): 55-59.

9. Chhetri MK. Parasitic infection in Nepal. JNMA. 1997; 35: 6065.

10. Shiyama S, Rai SK, Ono K, Uga S. Small-scale study on intestinal parasitosis in a remote hilly village in Nepal. Nepal Med Coll J. 2003; 5(1): 28-30.

11. Sharma BK, Rai SK, Rai DR, Choudhury DR. Prevalence of intestinal parasitic infestation in schoolchildren in the northeastern part of kathmandu valley, Nepal. SOUTHEAST ASIAN J TROP MED PUBLIC HEALTH. 2004;35(3): 501-505.

12. Rai SK, Nakanishi M, Upadhyay MP, Rai CK, Hirai K, Ohno Y et al.
Effect of intestinal helminth infection on some nutritional parameters among rural villagers in Nepal. Kobe J Med Sci1998; 44(2): 91-98. 